\title{
Os nomes de origem indígena dos municípios paulistas: uma classificação
}

DOI: http://dx.doi.org/10.21165/el.v50i2.2865

\section{Eduardo de Almeida Navarro'}

\section{Resumo}

Um fato que chama a atenção ao se observarem os nomes dos municípios do estado de São Paulo é a forte presença de topônimos com origem em línguas indígenas. Quase trinta e sete por cento deles são derivados do Tupi Antigo, da Língua Geral Paulista, do Guarani, do Nheengatu e de outras línguas não Tupi. Foram atribuídos por falantes dessas línguas, espontaneamente, entre os séculos XVI e XIX, ou por não falantes delas, artificialmente, no século XX. Nosso trabalho visa a analisar tais topônimos e classificálos de acordo com as línguas de onde provieram e de acordo com a sua adequação ou inadequação linguística e/ou geográfica. Procuramos também compreender as causas da intensa nomeação artificial em línguas indígenas no século XX, um dos fenômenos socioculturais mais interessantes do Brasil no século passado.

Palavras-chave: toponímia; estado de São Paulo; línguas indígenas.

1 Universidade de São Paulo (USP), São Paulo, São Paulo, Brasil; edalnava@yahoo.com.br; http://orcid.org/0000-0002-8001-8766 


\title{
Classification of indigenous origin names of the municipalities of São Paulo state
}

\begin{abstract}
A fact that draws attention when observing the names of São Paulo's municipalities is the strong presence of toponyms with origins in indigenous languages. Almost thirtyseven percent of them are derived from Ancient Tupi, from Língua Geral Paulista, Guarani, Nheengatu, and other non-Tupi languages. They were assigned by speakers of such languages, spontaneously, between the 16th and 19th centuries, or by non-speakers of such languages, artificially, in the 20th century. Our paper aims at analyzing such toponyms and classifying them according to the languages from which they originated and according to their linguistic and/or geographical adequacy or inadequacy. We also seek to understand the causes of the intense artificial naming in indigenous languages in the 20th century, one of the most interesting socio-cultural phenomena in Brazil in the last century.
\end{abstract}

Keywords: place names; state of São Paulo; indigenous languages

\section{Introdução}

O sistema toponímico paulista é constituído majoritariamente de nomes em língua portuguesa. Alguns de tais nomes remontam às primeiras décadas após o descobrimento do Brasil, em 1500. Outros são nomes muito recentes. Em seguida vêm os nomes de origem indígena, alguns também muito antigos, remontando ao século XVI ou, mesmo, à pré-história brasileira, e outros muito recentes, criados artificialmente no século $X X$, quando já não se falavam mais aquelas línguas de maior importância histórica e toponomástica para o estado de São Paulo, a saber, o Tupi Antigo e a Língua Geral Paulista (ou Língua Geral Meridional). Ao nos referirmos a tais nomes como sendo de origem indígena, estamos considerando somente os morfemas em si, sem levarmos em conta se eles foram criados por falantes nativos ou não. Pode-se dizer que o nome arara, enquanto um morfema, seja de origem tupi. Os topônimos, porém, podem ser criações artificiais, à medida que não tenham sido atribuídos por falantes da língua da qual se originaram. Assim, ao tratarmos de topônimos de origem indígena, estamos considerando somente o nome do ponto de vista de sua forma. Isso para evitarmos ambiguidade, fazendo outrem supor a existência de um nomeador indígena, o que, muitas vezes, não é o caso.

Além disso, é preciso considerar que os nomes de origem indígena de que aqui tratamos seguem os processos fonético-fonológicos da língua portuguesa. Assim, fones não existentes em português realizam-se de diferentes formas no caso dos topônimos. É o que ocorre, por exemplo, com o fone [i] do tupi antigo, que se realiza em português como 
[i] ou [u]. O mesmo ocorre com o fone [ $\beta$ ] daquela língua, que se realiza como [b] ou [v]. Com relação à consoante oclusiva glotal [?], ela desaparece nos nomes portugueses de origem indígena.

Dos 645 municípios do estado de São Paulo, 238 têm nomes que, total ou parcialmente, são de origem indígena, isto é, quase 37 por cento do total.

O atual estado de São Paulo ocupa um território que, pelo Tratado de Tordesilhas, de 1494, estendia-se, em sua maior parte, por terras que caberiam à Espanha. Em território que caberia a Portugal, São Paulo estendia-se pelas capitanias de São Vicente, Santo Amaro e São Tomé, conforme a divisão delas feita por El-Rey D. João III na década de 30 do século XVI.

A presença europeia no que é o atual estado de São Paulo remonta aos primeiros anos dos Quinhentos. Habitavam o litoral de São Vicente índios que falavam o Tupi Antigo. Índios falantes dessa língua adentravam também o interior, pelo Vale do Tietê, por centenas de quilômetros. Havia, ademais, nas capitanias mencionadas, outros índios que Ihes eram aparentados linguisticamente, como os tamoios (tupinambás) e os tupiniquins, além de índios não tupis, falantes de línguas do tronco Macro-Jê.

Os europeus tiveram, desde cedo, de aprender a língua da costa. Com efeito, a população de índios era imensamente superior à população europeia. Assim, muitas vezes, os nomes indígenas dos lugares foram usados pelos europeus e muitos deles mantiveram-se até os dias de hoje. É caso de topônimos como Anhangabaú, Itanhaém, Peruíbe, Paranapiacaba etc.

Desde as primeiras décadas do século XVI, desenvolveu-se na capitania de São Vicente um próspero tráfico de escravos índios. Organizavam-se incursões ao interior com tal objetivo. A Língua Brasílica, nome colonial para o Tupi Antigo, avançava rumo ao interior no século XVII. Formava-se lentamente a Língua Geral Meridional ou Paulista, à medida que as bandeiras dos vicentinos tomavam contato com os guaranis das atuais terras de Mato Grosso do Sul e com índios falantes de línguas do tronco Macro-Jê. A Língua Geral Paulista foi, assim, supra-étnica, isto é, falada não somente por índios Tupis, mas também por europeus, escravos africanos e índios de outras línguas e etnias. Ela teve influências também do Guarani, dados os contatos que os paulistas mantiveram com seus falantes no Paraguai e em outras regiões que atualmente fazem parte do Brasil, como o oeste do Paraná, de Santa Catarina, do Rio Grande do Sul e do Mato Grosso do Sul.

Os vicentinos, nos três primeiros séculos do Brasil colonial, avançaram rumo ao interior em várias direções. Foram eles os que descobriram as Minas Gerais, os primeiros civilizados que chegaram às terras de Goiás, de Mato Grosso (hoje dividido em dois estados), os 
primeiros a devassarem as terras do Paraná, de Santa Catarina, do Rio Grande do Sul. Foi-se constituindo o que Alfredo Ellis Jr. (1951), historiador paulista da primeira metade do século XX, chamou de Paulistânia, isto é, o vasto interior colonizado e influenciado cultural e socialmente pelos paulistas.

O Tupi Antigo desapareceu no final do século XVII e, na vasta Paulistânia, a Língua Geral Paulista passou a tomar-lhe o lugar em meados dos Seiscentos, tendo sido usada até o final do século XIX, desaparecendo naquela época com a grande onda migratória europeia para a província de São Paulo. Ela deixou poucos documentos escritos, mas muitos topônimos com origem nessa língua são perfeitamente reconhecíveis: Butantã, Bussocaba, Botucatu, Votorantim, Botujuru etc.

O século XVIII assistiu ao surgimento de uma nova formulação teórica acerca da sociedade humana: o lluminismo. Um de seus maiores representantes, Jean Jacques Rousseau, nobilitou o índio ao criar o mito do bom selvagem. Conforme nos mostrou Melo Franco (1991), os textos dos cronistas e dos viajantes quinhentistas e seiscentistas forneceram as informações etnológicas de que Rousseau se serviu para formular aquela representação do homem americano. As mazelas da civilização são questionadas com base num passado idealizado, livre da opressão e da desigualdade. Tais ideias conduziram a formulações teóricas libertárias que levariam às revoluções burguesas e serviram de referência para as ideias de democracia, de igualdade dos homens perante a lei, de direitos fundamentais do ser humano, ou seja, o que define em linhas gerais o projeto da Idade Contemporânea.

No plano estético e intelectual, o Romantismo foi a consequência de tais concepções do homem e do mundo no século XIX. As tradições históricas e nacionais deveriam suplantar os modelos provindos da Antiguidade Clássica. Os pastores da Arcádia dariam lugar a outros paradigmas humanos, relacionados ao passado das diferentes nações. No Brasil, um deles foi o índio, não o que vivia ainda no interior e nos sertões do país, mas o que os havia habitado em outros séculos. Surge, assim, um índio mitificado, que forneceria representações à cultura brasileira dos Oitocentos, inclusive à sua literatura e à sua onomástica. O nacionalismo brasileiro gesta-se a partir de tais fundamentos ideológicos. Neles também se basearão as formas de nacionalismo político surgidas no século XX, como o Integralismo de Plínio Salgado.

O mito do Tupi, como já foi chamado tal fenômeno no Brasil, bem analisado na obra de Schwamborn (1998), teve, assim, muita vitalidade e contribuiu para nobilitar um tipo humano ancestral do país.

Em 1901, ao publicar a obra O Tupi na Geografia Nacional, o engenheiro baiano Teodoro Sampaio, que participou de importantes obras de saneamento da capital paulista no início do século XX, iniciava a Tupinologia no Brasil, um ramo de estudos das línguas indígenas 
brasileiras que encontraria boa fortuna nas décadas seguintes. Sua obra influenciou os literatos e artistas que inauguraram o Modernismo no Brasil, com a Semana de Arte Moderna de 1922 e foi muito usada para a criação de topônimos naquela década.

Em 1928, Oswald de Andrade, parafraseando Shakespeare, apresentava em seu Manifesto Antropofágico a ideia de que o dilema do Brasil seria Tupi or not Tupi. O indianismo modernista traria novos contornos ao indianismo árcade e ao romântico, dos séculos anteriores.

Em 1935, um ano após a fundação da Universidade de São Paulo, foi criada em sua Faculdade de Filosofia, Ciências e Letras a cadeira de Língua Tupi, tendo à frente dela o professor Plínio Ayrosa. Naquela época ainda não havia clareza das diferenças entre o Tupi Antigo, as línguas gerais dele provenientes e o Guarani. Com efeito, não se conhecia bem qual fosse o léxico do Tupi Antigo, uma vez que não se publicara ainda um dicionário dele. Muitos creram na existência do Tupi-Guarani, que é, na verdade, uma família linguística e não uma língua específica.

O Brasil vivia na década de trinta do século XX um momento histórico de forte nacionalismo político, reflexo da ascensão do nazifascismo na Europa. Contudo, a derrota do eixo na Segunda Guerra Mundial criava um ambiente político desfavorável à ditadura de Vargas, o que levaria à sua deposição em 1945. Com sua recondução ao poder por meio do voto popular, em 1950, novo alento tomou seu ideário nacionalista. Com efeito, poucos dias após seu suicídio, o recém-empossado presidente Café Filho, em 3 de setembro de 1954, sancionava a Lei $n^{\circ} 2311$, que instituía em todas as faculdades de Filosofia e Letras do país a cadeira de Etnografia Brasileira e Língua Tupi. Eram os últimos ecos de um projeto nacionalista que já não encontrava ambiente propício no mundo do Pós-Guerra.

\section{Metodologia}

Utilizamos, para a presente pesquisa, dados obtidos do Instituto Brasileiro de Geografia e Estatística (IBGE), que traz informações históricas sobre todos os municípios brasileiros, incluindo-se aí os 645 municípios paulistas. Classificamos os nomes de origem indígena de tais municípios sob dois aspectos:

a) Quanto às línguas das quais se originaram;

b) Quanto à sua adequação geográfica e linguística, quando se tratar de nomes criados artificialmente no século XX e atribuídos por não falantes de línguas indígenas.

Quanto às línguas das quais se originaram os topônimos, classificamo-los em nomes com origem no Tupi Antigo ou na Língua Geral Paulista, no Guarani, no Nheengatu, em línguas do 
tronco Macro-Jê, em Quíchua ou em nomes híbridos, isto é, criados com palavras de mais de uma língua. Para isso, utilizamos os vocabulários de Barbosa (1971) e Viégas (1971), os dicionários de Carvalho (1987) e Navarro (2013) para o Tupi Antigo, o de Stradelli (1929) para o Nheengatu e os de Montoya (1639) e Guasch (1948) para o Guarani. Finalmente, utilizamos a obra de Cardoso (1961) para línguas não Tupi (as do Tronco Macro-Jê e as da América Andina). Para a análise dos nomes híbridos, foram utilizadas todas as obras acima citadas.

As classes de topônimos analisados basearam-se fundamentalmente no significante, isto é, no nome em si. Assim, por exemplo, no caso de Arandu, o significante, o termo em si, permite classificá-lo como Guarani. A existência do fenômeno da queda da sílaba pós-tônica, a diferenciar palavras do Tupi Antigo e do Guarani, permite-nos facilmente reconhecer as desta última origem. É o que sucede, por exemplo, com os nomes Cajati, Itaberá, Itaju, Ipiguá, Guapiaçu, Piraju e Tuiuti. Se tivessem origem no Tupi Antigo, escreverse-iam Cajatiba, Itaberaba, Itajuba, Ipiguara, Guapiruçu, Pirajuba e Tuiutiba. O mesmo se diga de Votorantim, que tipifica uma classe de nomes que incluem os étimos butura, votura, botura, da Língua Geral Paulista (como Botucatu, Votuporanga etc.), o que permite classificá-lo imediatamente como originário desta língua geral.

Deste modo, foi considerado o nome enquanto uma palavra e não o ato de sua atribuição a algum lugar, o que produziria problemas de difícil resolução. Com efeito, o nome em si pode ser espontâneo (como é o caso do nome do Rio Tietê, criado em tempos imemoriais, podendo remontar, inclusive, aos tempos pré-cabralinos, isto é, à pré-história do Brasil), mas a atribuição dele a algum lugar pode ser artificial (como a nomeação do município paulista de Tietê, em época conhecida, isto é, o ano de 1867). O nome Tietê, por provir do hidrotopônimo Rio Tietê, que percorre todo o estado de São Paulo, poderia ter sido atribuído a centenas de diferentes adensamentos humanos situados às suas margens. 0 fato de ter sido atribuído a uma vila em especial, já no século XIX, implica artificialidade.

Assim, o nome escolhido para a nomeação de um município pode provir de palavras ou de composições historicamente registradas, figurando em textos coloniais ou fazendo parte do léxico de línguas indígenas ou de línguas gerais. Pode ter sido atribuído por falantes de tais línguas ou pode, também, ter sido criado artificialmente, numa época em que a língua na qual o nome em questão foi gerado não era mais falada. O nome indígena pode, enfim, ter sido atribuído por não falantes de línguas indígenas, sendo aquele, no entanto, muito antigo e criado quando tais línguas eram efetivamente usadas.

Em todo o mundo, a toponímia artificial incide notadamente sobre os adensamentos humanos: cidades, distritos, vilas etc. Já os nomes dos elementos físico-naturais do espaço, tais como, rios, riachos, morros, serras etc., eles são muito resistentes a mudanças e a nomeações artificiais e quase sempre provêm de nomeações espontâneas no passado, mas que podem ocorrer novamente séculos depois, desta vez de modo artificial. 
Não criamos aqui classes separadas para os nomes com origem no Tupi Antigo e na Língua Geral Paulista. Isso porque, muitas vezes, é impossível saber se aqueles nomes não surgiram muito antes da época em que foram registrados pelos colonizadores. Assim, um nome anotado no século XVIII, em que a Língua Geral Paulista foi amplamente falada, pode remontar aos séculos anteriores e isso geraria conclusões equivocadas sobre a língua em que o nome foi formado. Com efeito, como os nomes que se referem aos aspectos físicos do espaço geográfico tendem a manter-se durante séculos, seria difícil, em certos casos, saber se tiveram origem no Tupi Antigo (falado até o final do século XVII) ou se a tiveram na Língua Geral Paulista, falada de meados dos seiscentos até meados do século XIX.

No caso de nomes mistos, tomamos para análise somente o nome de origem indígena. Tal é o caso do nome Embu das Artes, em que, ao nome registrado em textos quinhentistas, Embu, foi acrescentada, por ato oficial, em 2011, a expressão das Artes.

Há casos em que as informações históricas fornecidas pelo IBGE são imprecisas acerca do significado que o criador do topônimo queria que ele tivesse. Por exemplo, sobre o nome do município de Jarinu há a informação de que ele significaria Campo Largo. No entanto, o brasão daquele município exibe no seu centro uma palmeira. Assim, é provável que a intenção do nomeador tenha sido criar um topônimo com o significado de campo das palmeiras jarás.

Quanto à adequação dos topônimos artificiais, classificamo-los em duas categorias principais:

Topônimos adequados - São aqueles formados corretamente e atribuídos a lugares onde as línguas das quais se originaram foram efetivamente faladas. Ou, ainda, são nomes de origem Tupi já incorporados ao léxico do português. Se compostos, obedecem às regras de composição das línguas das quais se originaram.

\section{Topônimos inadequados:}

Do ponto de vista geográfico: formados corretamente do ponto de vista gramatical, mas atribuídos a lugares onde a língua da qual se originaram nunca foi falada. Um nome geograficamente inadequado pode ser também aquele que remete a fatos naturais que não são próprios do lugar que ele nomeia.

Do ponto de vista linguístico: formados incorretamente, sem respeito às regras de composição das línguas das quais se originaram ou com errada ortografia, semântica etc. Contudo, tais topônimos nomeiam lugares em que as línguas usadas em sua criação foram faladas no passado. Às vezes, quando a intenção do nomeador não for 
bem conhecida, isto é, quando não se souber que sentido quis dar ao nome que criou, levaremos em conta a mera forma deste. Se puder ser considerado um nome com origem indígena, não o trataremos como linguisticamente inadequado.

Após a pesquisa da história dos municípios paulistas e da origem indígena de seus nomes, elaboramos o Quadro I, em que os topônimos aparecem classificados segundo os critérios anteriormente apresentados. Ao lado de todos os topônimos aparecem os anos em que eles foram atribuídos a algum adensamento humano. Quanto aos topônimos linguisticamente inadequados e inconsistentes, eles estão acompanhados por três asteriscos $(* \star *)$.

Quadro 1. Classificação dos nomes de origem indígena atribuídos aos municípios paulistas (O ano de criação do distrito, do patrimônio, da freguesia, da vila ou do município que leva o nome em questão aparece entre parênteses.)

\begin{tabular}{|c|c|}
\hline 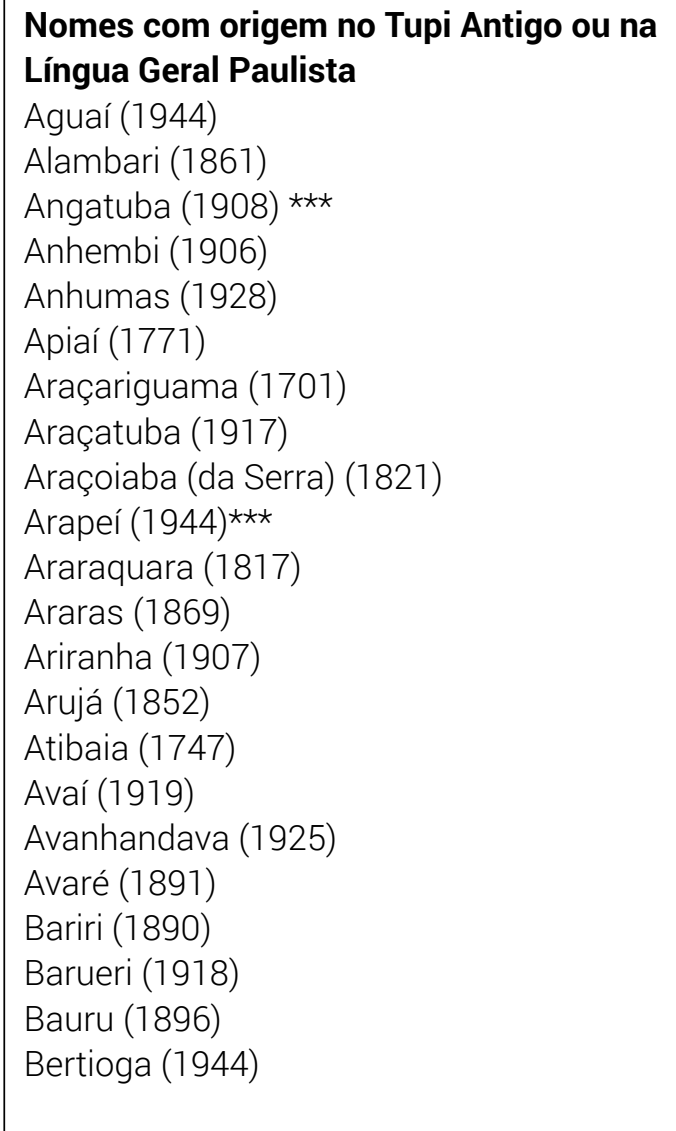 & 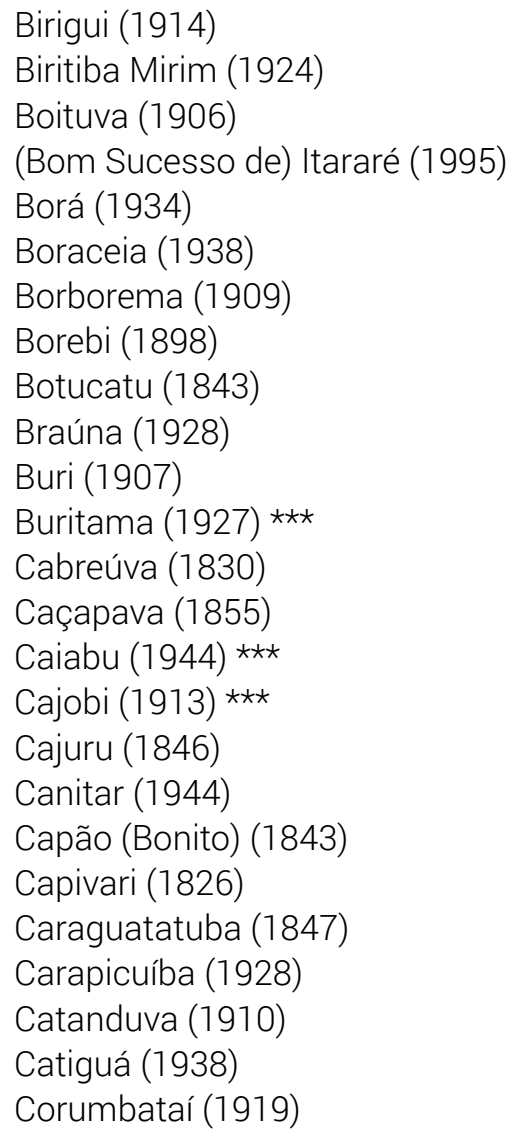 \\
\hline
\end{tabular}




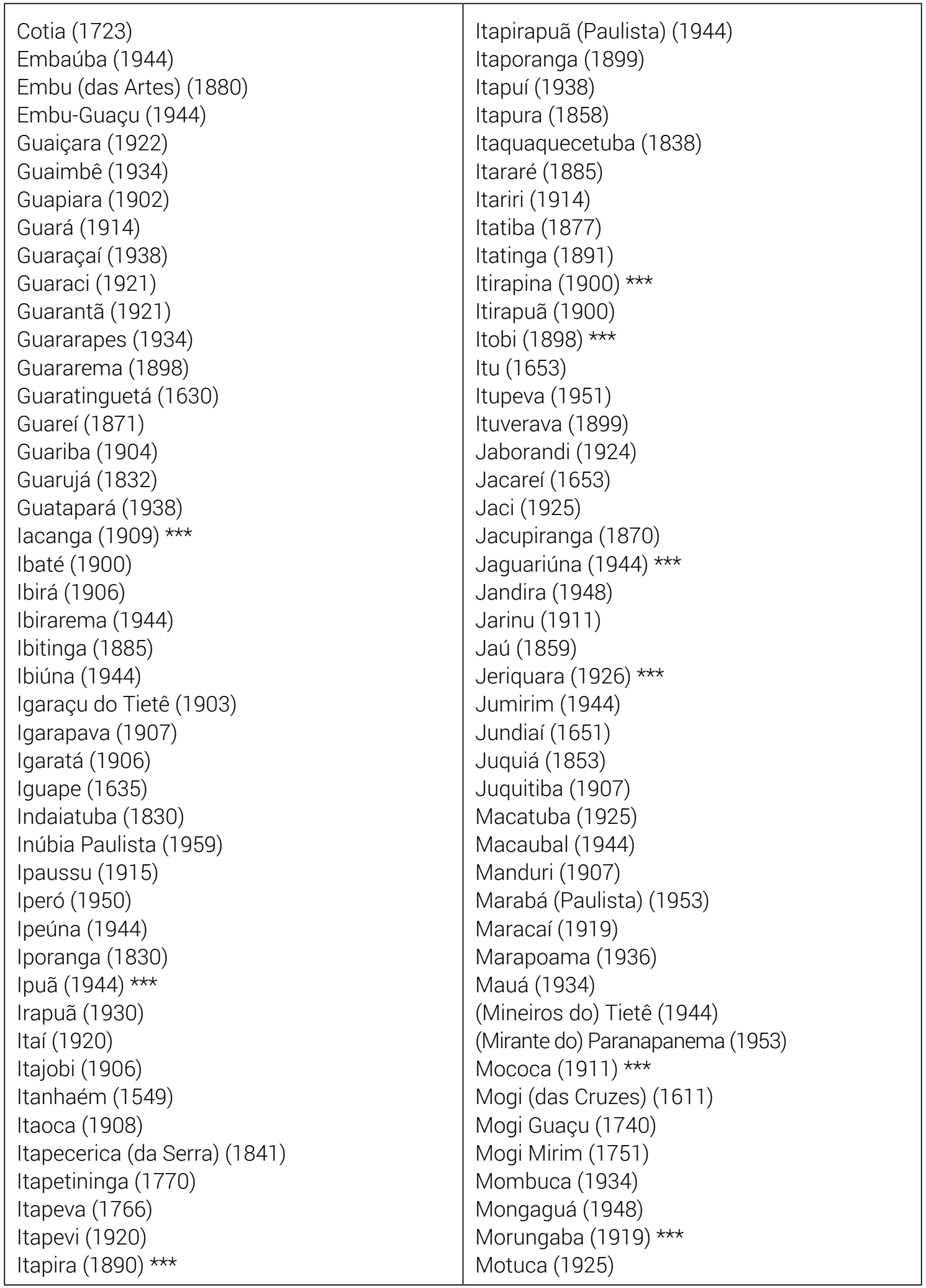




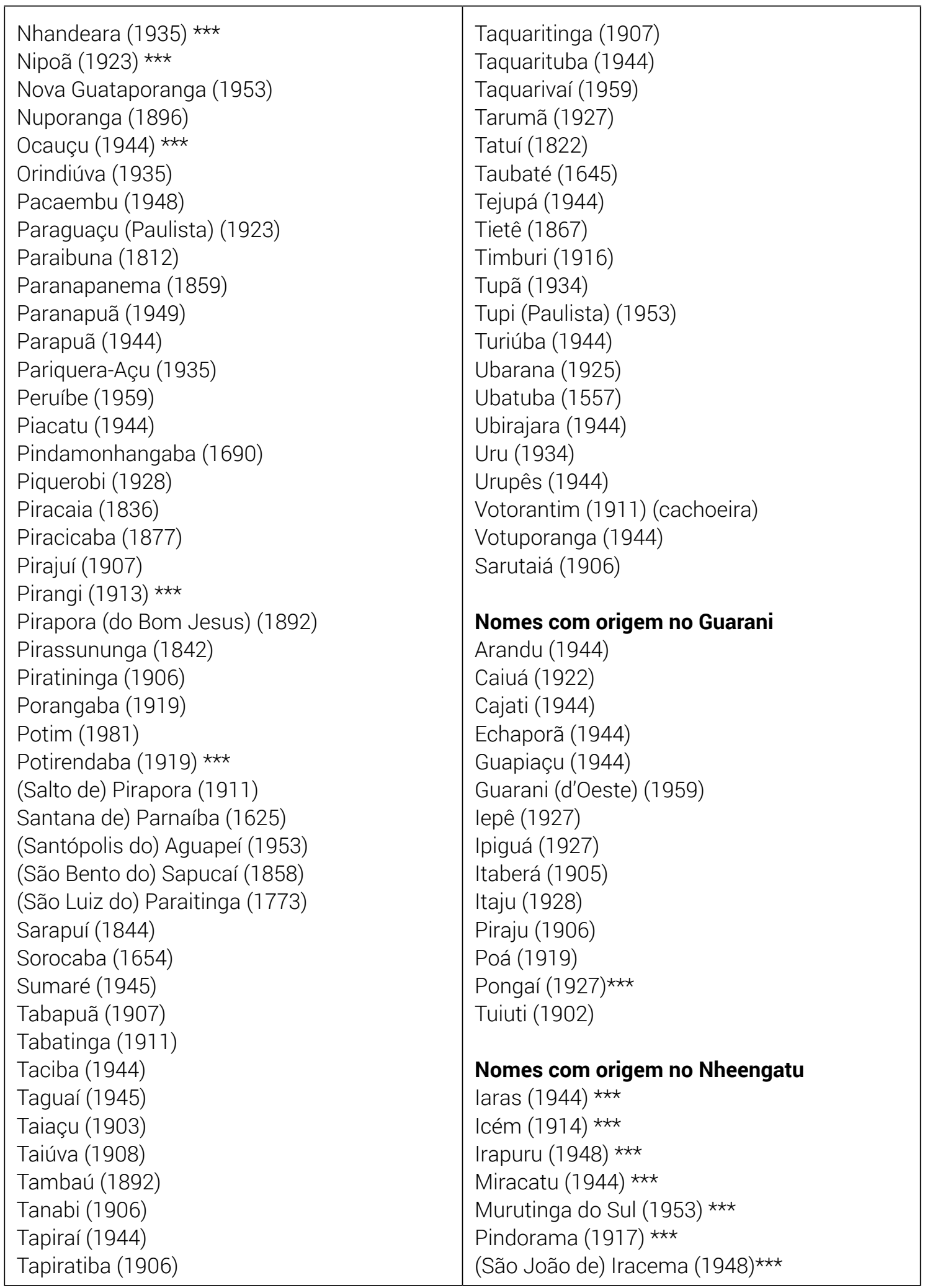




\begin{tabular}{|c|c|}
\hline $\begin{array}{l}\text { Nomes com origem em línguas do tronco } \\
\text { Macro-Jê } \\
\text { Chavantes (1917) } \\
\text { Guarulhos (1600) } \\
\text { lacri (1938) } \\
\text { Tremembé (1866) } \\
\text { Nome com origem no Quíchua } \\
\text { Guaíra (1908) } \star \star \star ~\end{array}$ & 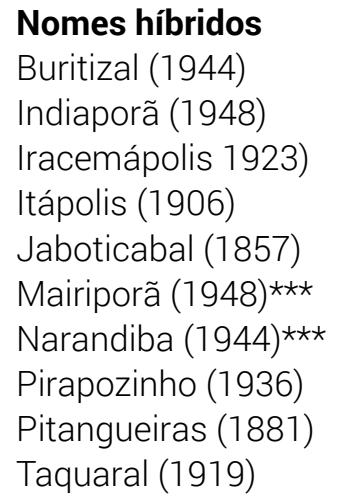 \\
\hline
\end{tabular}

\section{Análise dos topônimos classificados no Quadro 1}

- Dos 238 nomes de municípios paulistas com origem em línguas indígenas, 30 foram considerados inadequados linguística e/ou geograficamente.

Gráfico 1. Número de municípios com nomes de origem indígena em relação ao total

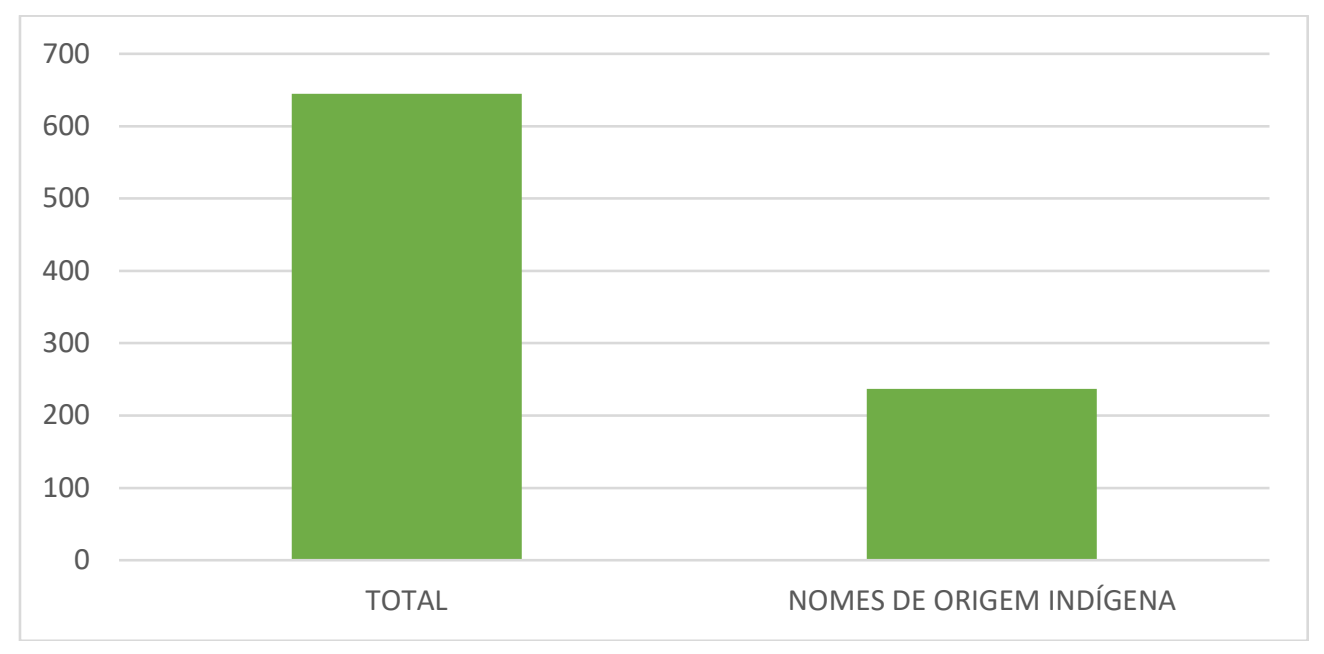

Fonte: Elaboração própria

A nomeação em línguas indígenas de adensamentos humanos (freguesias, vilas, distritos, municípios etc.) feita por iniciativa oficial ocorreu no Brasil principalmente no século XX. Grande número deles, porém, são hidrotopônimos, orotopônimos, zootopônimos ou fitotopônimos e são muito mais antigos que os povoamentos aos quais foram atribuídos, remontando sua origem aos tempos coloniais. Os topônimos artificiais foram quase todos criados na primeira metade do século XX. Após a década de 50, em que foram criados 12 topônimos, houve apenas mais uma criação de nome de município de origem indígena no estado de São Paulo, o de Bom Sucesso de Itararé, em 1995. 
- O ano de 1944 destaca-se por ser de grande produtividade toponímica, sendo que 35 topônimos surgiram então (cerca de 15\% do total). Isso foi consequência do decreto-lei n. 5.901 do presidente Getúlio Vargas, de 21 de outubro de 1943, que estabelecia normas para a "eliminação no país, da repetição de topônimos de cidades e vilas". O artigo 70, III desse decreto-lei rezava o seguinte:

Como novos topônimos deverão ser evitadas designações de datas, vocábulos estrangeiros, nomes de pessoas vivas, expressões compostas de mais de duas palavras, sendo, no entanto, recomendável a adoção de nomes indígenas ou outros com propriedade local.

- Dos 238 topônimos de origem indígena, 202 tiveram origem no Tupi Antigo ou na Língua Geral Paulista, 14 no Guarani, 7 no Nheengatu, 4 em línguas do tronco Macro-Jê, 1 em Quíchua e 10 híbridos.

- Há diversos nomes tomados da obra O Tupi na Geografia Nacional, de Teodoro Sampaio, que, com muitas etimologias equivocadas, contribuiu para a criação de topônimos inadequados. As informações históricas fornecidas pelo IBGE, provindas de fontes locais, citam frequentemente aquele autor.

\section{Os topônimos inadequados}

Dos 238 topônimos de origem indígena, 22 foram aqui considerados inadequados do ponto de vista linguístico, ferindo regras de composição, de derivação ou tendo sido formados com lexemas inexistentes nas línguas indígenas em que seus idealizadores pretendiam que tivessem origem. Tais topônimos são os seguintes:

Angatuba (1908) - A criação desse topônimo foi uma tentativa de traduzir parcialmente o nome da Freguesia do Espírito Santo da Boa Vista, existente desde 1872. Talvez seu criador quisesse traduzir algo como Lugar do Espírito (Santo). O nome em questão, porém, poderia significar, em Língua Geral Paulista, Ocorrência do Espírito, Ajuntamento de Espíritos. Se a intenção do nomeador foi criar um nome em Tupi Antigo, foi desrespeitada uma regra de composição nesta língua e o nome deveria ter sido Anduba e não Angatuba.

Arapeí (1944) - Tal nome figura na obra de Theodoro Sampaio já mencionada: "Arapehy s.c. Arabé-y, o rio das baratinhas, dos lambaris" (p. 198). Com efeito, conforme as informações históricas que o IBGE fornece sobre tal município, foi criado um 1891 um distrito com o nome de Alambari, subordinado ao município de Bananal. Tal distrito foi extinto em 1892 e seu território foi anexado ao município de Bananal. Em 1944, é novamente criado o distrito, então com a denominação de Arapeí, também subordinado àquele município mencionado. 
Como se vê, novamente a obra de Sampaio contribuiu para a criação de topônimo inadequado. Nenhum dicionário consigna arabé como sendo "lambari". Sucede que, por força do mencionado decreto-lei de 1943 que determinava que não poderia haver nomes iguais de municípios brasileiros e já existindo os municípios de Alambari, em São Paulo, e Lambari, em Minas Gerais, optou-se por Arapeí, que absolutamente não significa o que os criadores do referido topônimo queriam designar.

Buritama (1927) - A forma correta seria, em Tupi Antigo, Buriretama. O segundo elemento da composição está indevidamente reduzido.

Caiabu (1944) - Tal nome teve por fonte, certamente, a obra de Sampaio, que, na p. 212, escreve o seguinte: "CAIABÚ corr. CAÁ-YBÚ, a fonte ou olho d'água da mata". Ora, tal etimologia, em Guarani, é correta, mas nada indica que fosse essa a intenção do nomeador ao criar o nome Caiabu.

Cajobi (1913) - O IBGE informa que tal nome seria a tradução do antigo nome do distrito de paz de Monte Verde, o que é incorreto. É possível que a etimologia dada pelo IBGE esteja equivocada e que a intenção do nomeador tenha sido outra. Com efeito, tal nome poderia provir de cajubi, cajubim da língua geral meridional, designações comuns de certas aves galiformes, cracídeas.

lacanga (1909) - Pretendeu-se, aqui, traduzir com tal nome "cabeceira de rio". Não há nenhum fundamento para isso, pois o termo akanga, do Tupi Antigo, não inclui tal sentido. Segundo o IBGE, Theodoro Sampaio teria dado a tal nome a etimologia de "nascente d'água", o que não tem fundamento.

Ipuã (1944) - A criação de tal nome foi uma tentativa de se traduzir o topônimo Olhos d'Água, distrito do município de São Joaquim. Ocorre que olhos d'água, em Tupi Antigo, traduz-se por 'Ytororoma.

Itapira (1890) - O nome mais adequado seria, aqui, Itabira, para traduzir parte de seu antigo nome: Penha (do Rio do Peixe).

Itirapina (1900) - A forma adequada seria Ibitirapina. O primeiro elemento da composição está indevidamente reduzido.

Itobi (1898) - A criação de tal nome foi uma tentativa de se traduzir o topônimo Rio Verde, nome antigo de um distrito de Casa Branca, SP. Contudo, a forma correta seria Iobi (para ter origem no Tupi Antigo: ' $y$-oby). 
Jaguariúna (1944) - A intenção do nomeador foi traduzir para o Tupi Antigo "rio da onça preta". O nome, contudo, significa "rio preto da onça". Isso porque o adjetivo un foi posposto ao segundo termo da composição (' $y>$ > i).

Jeriquara (1926) - Se, de fato, a intenção do nomeador foi traduzir "refúgio das tartarugas", em Tupi Antigo (etimologia que o IBGE apresenta para o referido nome), temos, aqui, uma composição incorreta. A forma mais adequada seria Jeriquaquara ou, ainda melhor, Juruquaquara (de îurukûá - "tartaruga marítima" + kûara, "buraco", "refúgio"). 0 primeiro elemento da composição está indevidamente reduzido. Sucede, ademais, que o município em questão situa-se no interior e não no litoral, onde vivem as tartarugas marítimas chamadas îurukûá, em tupi antigo (Marcgrave, 241). É possível que a etimologia apresentada pelo IBGE esteja equivocada e que o nome do município provenha de îurikûara, nome de erva que cresce na floresta, que era usada para curar úlceras venéreas malignas (Piso, 196).

Mairiporã (1948) - O nome é híbrido e tal hibridismo teve como causa o desconhecimento das diferenças entre o Nheengatu e o Guarani por parte de seu criador: mairi, em Nheengatu é cidade e porã é palavra Guarani, significando bonito(a).

Mococa (1911) - Tal nome foi criado no século XX e, talvez, sob influência da obra de Theodoro Sampaio (1987, p. 284), que apresenta a seguinte etimologia para ele: "Mococa corr. Mô-coga, fazer roça; o roçado; a plantação".

Tal etimologia se Sampaio é completamente equivocada e tal nome somente pode significar "casa de mocós" (do Tupi Antigo mokó-oka, "refúgio de mocós", roedor caviídeo (Kerodon rupestris), encontrado desde o PI até MG. Assim, dependendo do sentido pretendido para tal nome, ele será linguisticamente inadequado ou não.

Morungaba (1919) - Tal nome foi tomado da obra de Teodoro Sampaio citada anteriormente. Segundo esse autor, aquele nome significaria baliza (o que não tem fundamento), podendo proceder também de "morangaba [...], que exprime beleza, formosura" (SAMPAIO, 1987, p. 286). O IBGE, contudo, informa que o nome significa "colmeia" ou "lugar onde moram as abelhas", o que é um absurdo.

Narandiba (1944) - Tentou-se criar, aqui, um nome que traduzisse laranjal. O nome é híbrido e tal hibridismo teve como causa o desconhecimento das diferenças entre o Tupi Antigo e o Guarani por parte de seu criador. Ndiba é forma nasalizada de tyba, termo do Tupi Antigo que significa ocorrência, ajuntamento. No entanto, o termo narã não é Tupi, mas Guarani. 
Nhandeara (1935) - A forma adequada seria Nhandeiara, para traduzir Nosso Senhor. 0 termo está indevidamente reduzido.

Nipoã (1923) - Segundo o IBGE, a criação de tal nome foi uma tentativa de se traduzir campo redondo. Se essa tiver sido a intenção do nomeador, o topônimo deveria ser, então, Nhuapuá.

Ocauçu (1944) - Aqui houve desrespeito a uma regra de composição do Tupi Antigo, pois nunca se usa o sufixo nominalizador -a na fronteira de palavras. A forma adequada seria, assim, Ocuçu.

Pirangi (1913) - Aqui houve desrespeito a uma regra de composição do Tupi Antigo, pois se antepôs o adjetivo qualificativo ao substantivo. A forma correta seria Ipiranga, para traduzir rio vermelho.

Pongaí (1927) - A criação de tal nome foi uma tentativa de se traduzir o topônimo Saltinho, patrimônio surgido em 1913. No livro de Teodoro Sampaio (1987, p. 306), aparece o verbete iniciado pelo lema ponga, que ele traduziu por "baque, a queda com ruído, o que se lança abaixo". Certamente foi daí que se tomou a palavra que originou aquele nome sem sentido. Ponga, em Tupi Antigo, é batida, percussão, donde gûyrá-ponga, "pássaro que bate", isto é, cujo canto parece os sons metálicos do bater de ferro em bigorna (Marcgrave, 201). Saltinho seria bem traduzido por Ituí, Ituim ou Itumirim (considerando-se a fonologia portuguesa). Pongaí significa, na verdade, batidinha.

Potirendaba (1919) - A forma adequada seria Ibotirendaba (lugar em que se assentam as flores das plantas). O primeiro elemento da composição, potyra, efetivamente significa, em Tupi Antigo, flor, mas é necessariamente possuível, e, assim, deveria ter sido escrito com um determinante ('ybotyra > ibotira: flores das plantas).

- Consideramos como geograficamente inadequados todos os topônimos artificiais com origem no Nheengatu e o nome Guaíra, de origem Quíchua. Com efeito, o Nheengatu é uma língua geral da Amazônia e não foi coerente nomearem-se municípios no estado de São Paulo com topônimos daquela origem. A única língua geral falada no estado de São Paulo foi o Tupi Austral. O Nheengatu é a Língua Geral Amazônica, também chamada Tupi Moderno (RODRIGUES, 1986, p. 39).

Com relação ao nome dos municípios de São João de Iracema e Iracemápolis, deve-se dizer que são provenientes da literatura romântica do século XIX, que teve grande importância na produção onomástica do Brasil. Os escritores românticos como José de Alencar (autor da obra Iracema) e Gonçalves Dias (autor de Últimos Cantos) foram influenciados tanto pelas gramáticas de Tupi Antigo (notadamente a do Padre Luís Figueira, publicada 
em 1621), quanto pelo Nheengatu da Amazônia. No caso do nome Iracema, ele está registrado nos Vocabulários de Stradelli (1929), do Nheengatu:

Iracema - enxame de abelhas (p. 475)

Assim, por essa razão supramencionada, consideramos tal nome como sendo de origem Nheengatu, uma vez que, em Tupi Antigo ou na Língua Geral Paulista, tal nome seria eisema, saída de mel ou, ainda, saída de abelhas. Com efeito, a etimologia apresentada para tal nome por José de Alencar em seu romance, isto é, lábios de mel, não tem fundamento.

Com relação ao nome Guaíra, que consideramos proveniente do Quíchua, língua que nunca foi falada em parte alguma do que hoje é o estado de São Paulo, alguns pretendem ser tal nome de origem Guarani. No entanto, há fortes evidências em contrário a tal hipótese. Cardoso (1961, p. 236) lembra, em abono da hipótese da origem quíchua do referido nome, que o principal porto da Venezuela chama-se La Guaira. Rojas (apud CARDOSO, 1961, p. 234, tradução nossa²) célebre americanista venezuelano, também atribuiu a tal topônimo origem quíchua (de huayra, equivalente a "vento", "brisa"):

E na topografia atual do Paraná, no estado brasileiro desse nome, figura o vocábulo Guaíra como nome de um salto e de uma ilha. Tudo isso nos prova que o vocábulo quíchua huayra foi aceito desde tempos remotos pela nação Guarani, que o substituiu por Guaíra. (tradução nossa).

Por outro lado, não vemos inadequação na nomeação de municípios com palavras de origem Guarani em algumas partes do oeste e noroeste paulista, uma vez que houve ali efetiva influência dessa língua no passado. Sucedeu, contudo, que, como já dissemos anteriormente, havia confusão, até mesmo nos meios universitários, sobre as diferenças entre o Tupi e o Guarani e a criação de certos topônimos pode ter sido fruto de tal equívoco. É difícil, contudo, especificar tais nomes e também os que são geograficamente inadequados em Tupi Antigo e em Língua Geral por não se terem informações precisas da geografia linguística de todo o território paulista.

2 No original: "Y en la topografía actual del Paraná, en la provincia brasilera de este nombre, figura el vocablo Guayra como nombre de un salto y de una isla. Todo esto nos prueba que el vocablo quéchua huayra fué aceptado desde remotos tiempos por la nación Guarani, que lo sustituyó con el de Guaira". (Aristides Rojas, Estudos históricos, 66) 
Gráfico 3. Língua indígena de origem dos nomes dos municípios paulistas

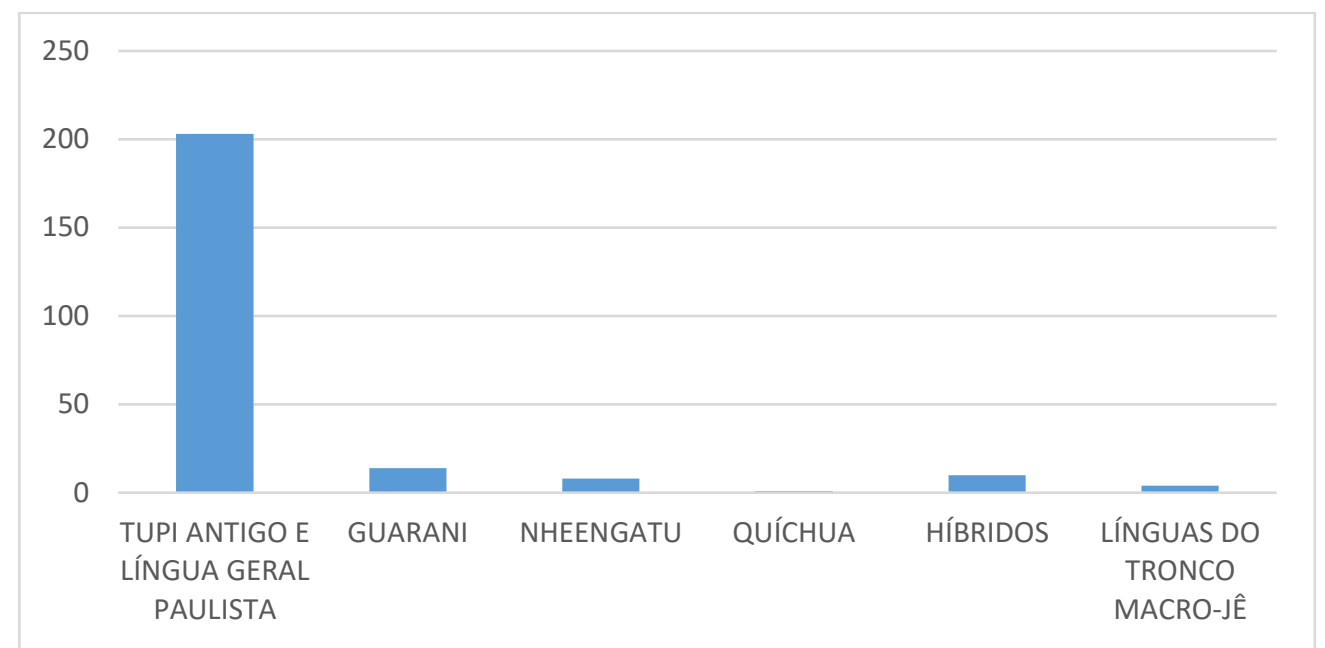

Fonte: Elaboração própria

\section{Conclusões}

São Paulo, por conta de sua história e de seu passado, ostenta grande porcentagem de topônimos espontâneos com origem no Tupi Antigo e na Língua Geral Paulista, nomes com centenas de anos de existência, criados por falantes daquelas línguas, quer índios, quer mamelucos, quer colonos luso-brasileiros.

Na nomeação de origem indígena de seus municípios, a de natureza artificial é maciçamente dominante. Isso não significa, como já mostramos anteriormente, que os nomes atribuídos aos lugares também sejam artificiais na mesma medida em que o é seu processo de nomeação. Com efeito, 2 de tais nomes foram oficializados no século $X V I, 11$ no século XVII, 9 no século XVIII, 50 no século XIX e 166 no século XX, quando não mais se falava o Tupi Antigo e a Língua Geral Paulista no estado de São Paulo. Sem dúvida alguma, tal fato explica-se pelo momento histórico em que grande parte do oeste paulista foi colonizado e incorporado à economia e à vida sócio-política da província (e depois estado) de São Paulo. Justamente por esse fato é que ocorreu nomeação artificial intensa na República Velha. A frente pioneira avançava e, ao mesmo tempo, o nacionalismo político fortalecia-se.

Assim, no prefácio da terceira edição de seu livro já mencionado, Teodoro Sampaio (1928, p.41) escreveu: 
A predileção dos brasileiros pelos nomes indígenas na denominação dos lugares é hoje tão acentuada que a toponímia primitiva vai aos poucos se restaurando e às localidades novas dão-se, de preferência, nomes tirados da língua dos ameríndios tupis. [...]

Há aqui um sentimento nacionalista, que se quer integrado e vívido, como que a dizer que, da raça americana, vencida, nem tudo se perdeu e que se, no sangue dos descendentes, a dosagem diminui a se apagar, a memória dos primitivos íncolas perdurará com os nomes dos lugares onde a civilização ostenta seus triunfos.

Na Era de Vargas, a nomeação de origem indígena foi, como se viu, incentivada por um decreto-lei. Porém, a partir da década de 50, a nomeação dessa natureza perdeu vigor. O Brasil passaria, com efeito, com o governo de Juscelino Kubitschek (1956-1960), a viver um novo momento histórico, caracterizado por desnacionalização econômica e abertura para o capital estrangeiro. Isso, sem dúvida, é uma das causas da ausência quase absoluta de novos nomes de origem indígena para os municípios paulistas a partir da década de 60.

Contudo, o mau conhecimento das diferenças entre o Tupi Antigo, as línguas gerais dele provindas e o Guarani, além do despreparo linguístico e gramatical dos criadores dos topônimos artificiais anteriormente apresentados (fossem fazendeiros, engenheiros, políticos e até professores universitários), levou a muitos erros e inadequações. Com efeito, $15 \%$ dos nomes apresentados são incorretos do ponto de vista gramatical, lexical ou geográfico, como a presente pesquisa mostrou.

Outro fato que chama a atenção é a ínfıma presença de línguas do tronco Macro-Jê na toponímia paulista. Se considerarmos a grande presença de índios Guaianá, Kaingang, Maromomi (ou Guarulhos) etc., todos falantes de línguas daquele tronco linguístico no passado do atual território paulista, é impressionante o fato de nomes delas não terem participado mais intensa e extensamente da nomeação dos lugares de São Paulo. Alguns existem (não a nomear municípios) e permanecem até hoje não traduzidos. Um deles é o nome Cumbica, provavelmente da língua dos Maromomi.

É preciso, finalmente, que se diga que os nomes artificiais surgidos no século XX não deslustram a riqueza da toponímia de origem indígena no estado de São Paulo. Muitos deles, provindos dos tempos coloniais, surgidos quando sua população efetivamente falava línguas indígenas, juntamente com o Português, constituem um patrimônio histórico imaterial incalculável. Há que impedir que eles sejam alterados por veleidades políticas, que podem, de forma irresponsável, eliminar esse vínculo que temos com o passado dos lugares. 


\section{REFERÊNCIAS}

ALENCAR, J. Iracema - Lenda do Ceará. Rio de Janeiro: Tipografia de Viana \& Filhos, 1865.

ANDRADE, O. Manifesto Antropofágico. Revista de Antropofagia, São Paulo, n. 1, p. 3-7, 1928.

BARBOSA. A. L. Pequeno Vocabulário Tupi-Português. Rio de Janeiro: Livraria São José, 1971.

CARDOSO, A. L. Toponímia Brasílica. Rio de Janeiro: Biblioteca do Exército, 1961.

CARVALHO, M. R. Dicionário Tupi (Antigo)-Português. Salvador: Empresa Gráfica da Bahia, 1987.

DIAS, A. G. Últimos Cantos. Rio de Janeiro: Typographia de F. de Paula Brito, 1851.

ELLIS JR., A. O café e a Paulistânia. São Paulo: Editora da Universidade de São Paulo, 1951.

GUASCH, A. Diccionario Guarani Castellano y Castellano Guarani. Buenos Aires: 1965 (edição do autor).

IBGE CIDADES. Brasília, Instituto Brasileiro de Geografia e Estatística. Disponível em: www.cidade.ibge.gov.br. Acesso em: 15 mar. 2020.

LEITE, R. A Língua Geral Paulista e o "Vocabulário Elementar da Língua Geral Brasílica". 1913. Dissertação (Mestrado em Linguística) - Instituto de Estudos da Linguagem, Universidade Estadual de Campinas, Campinas, 1913.

MARCGRAVE, G. História Natural do Brasil. São Paulo: Imprensa Oficial do Estado, 1942.

MELO FRANCO, A. A. O Índio Brasileiro e a Revolução Francesa: as origens brasileiras da teoria da bondade natural. Rio de Janeiro: Topbooks, 1991.

MONTOYA, A. R. Tesoro de la Lengua Guarani. Madrid: Iuan Sanches, 1639.

NASCENTES, A. Dicionário Etimológico da Língua Portuguesa. Rio de Janeiro: Gráfica Jornal do Comércio, 1955. 
NAVARRO, E. A. Dicionário de Tupi Antigo: A Língua Indígena Clássica do Brasil. São Paulo: Global Editora, 2019.

PISO, G. De medicina brasiliensi. São Paulo: Imprensa Oficial do Estado de São Paulo, 1948.

RODRIGUES, A. Línguas Brasileiras - Para o Conhecimento das Línguas Indígenas. São Paulo: Edições Loyola, 1986.

ROJAS, A. Estudios Históricos: Orígenes Venezolanos. Caracas: Imprenta y Litografia del Gobierno Nacional, 1891

SAMPAIO, T. O Tupi na Geografia Nacional. São Paulo: Companhia Editora Nacional, 1987.

SCHWAMBORN, I. O Guarani era um Tupi? Sobre os Romances Indianistas de José de Alencar. Fortaleza: Casa de José de Alencar / Programa Editorial, 1998.

STRADELLI, E. Vocabulários de língua-geral português-nheengatu e nheengatu-português. Revista do Instituto Histórico e Geográfico Brasileiro, Rio de Janeiro, v. 158, 1929.

VIEGAS, A. P. Vocabulário Português-Tupi, Tupi-Português. Campinas: Instituto Agronômico, Serviço de Divulgação Técnico-Científica, 1971. 